\title{
Anesthesiologists' Conduct Assessment towards the User of Cocaine at SUS Hospital with Accreditation. Knowledge through Questionnaire
}

\author{
Mateus Cardin Marquezani, $M D^{1}$, Luiz Eduardo Imbelloni, $M D, P h D^{2 *}$, Davi Pöttker, $M D^{1}$ \\ Eduardo Piccinini Viana, $M D^{2}$, Eduardo Piccinini Viana, $M D^{2}$, Jaime Weslei Sakamoto, $M D^{2}$, \\ André Augusto de Araujo, $\mathrm{MD}^{2}$ and Geraldo Borges de Morais Filho, MSc ${ }^{3}$ \\ ${ }^{1}$ Anesthesiology Resident, Hospital Clínicas Municipal de São Bernardo do Campo, SP - Brazil \\ ${ }^{2}$ Anesthesiologist, Hospital Clínicas Municipal de São Bernardo do Campo, SP - Brazil \\ ${ }^{3}$ Master in Labour Economics, UFPB, João Pessoa, PB, Government employee of the State of Paraiba, Brazil
}

\begin{abstract}
Introduction: In 1860, Albert Niemann isolated cocaine from leaves and reported that by placing the crystals on his tongue, and his tongue became benumb. In the Brazil is a country with greatest annual consumption rates becoming one of the biggest consumer markets of cocaine worldwide. The objective of this study, carried out through a questionnaire survey, was to find out the degree of knowledge of anesthesiologists from a tertiary hospital in their conduct towards a cocaine user.
\end{abstract}

Methods: The study is a research of descriptive exploratory, prospective, transversally cut, quantitative, through the application of a questionnaire in Department of Anesthesia with patients using cocaine. Anesthesiology residents of the hospital were excluded. The questionnaire (Appendix A) was applied from July to December 2020 with four identification questions and five open questions relevant to the objective of the study. To analyze the data, we use Descriptive Statistics graphs to profile the individual surveyed and build their respective distribution.

Results: The percentage of response was obtained in $66.6 \%$ of the teams, 28 men and 12 women. The duration of anesthesia practice ranged from 1 to 36 years. Of the 40 anesthetists, $75 \%$ suspend the surgery and $25 \%$ refer them to the operating room. All anesthesiologists find these patients during their month of work. Of the total $95 \%$ of anesthesiologists use clinical criteria. Of the 40 anesthetists, 36 believe that the guidelines for anesthesia in cocaine users should be reviewed.

Conclusion: Anesthesiologists, as perioperative physicians, have a vital role to play in the comprehensive care in patients with addiction to licit or to illicit drugs. The study showed that anesthesiologists need to be proactive and that there is a need to revise the guidelines for these patients.

Keywords

Cocaine, Crack, Addiction, Knowledge, Anesthesiologist

\section{Introduction}

Cocaine is an ancestor of modern anesthetics. It is an alkaloid (benzoylmethylecgonine) derived from coca leaves in the Andean region of South America. In 1860, Albert Niemann isolated cocaine from leaves and reported that by placing the crystals on his tongue, and his tongue became benumb [1]. This important fact of his brilliant dissertation was the early recognition of the anesthetic properties of cocaine.Cocaine has its anesthetic properties preserved in its derivatives, being still used as a local topical anesthetic, mainly in ear, nose and throat surgeries [2].
*Corresponding author: Dr. Luiz Eduardo Imbelloni, Coresponsible for CET-SBA, Anesthesiologist Hospital Clínicas Municipal de São Bernardo do Campo, Rua dos Coroados, 162 - Apto 45 - Bloco B, Vila Anastácio (Lapa), 05092-020 - São Paulo, SP - Brazil, Tel: + 55-11-99429-3637

Accepted: July 08, 2021

Published online: July 10, 2021

Citation: Marquezani MC, Imbelloni LE, Pöttker D, et al. (2021) Anesthesiologists' Conduct Assessment towards the User of Cocaine at SUS Hospital with Accreditation. Knowledge through Questionnaire. J Clin Anesth Pain Manag 5(2):227-231 
Citation: Marquezani MC, Imbelloni LE, Pöttker D, et al. (2021) Anesthesiologists' Conduct Assessment towards the User of Cocaine at SUS Hospital with Accreditation. Knowledge through Questionnaire. J Clin Anesth Pain Manag 5(2):227-231

In its illicit presentations it can be administered intranasally, injectable or through smoking and normally its effects last from 30 to 60 minutes [3]. It can cause ulceration of the nasal mucosa, anxiety, restlessness, tachycardia, hypertension, ventricular arrhythmias, asthma, pulmonary hemorrhage, thrombocytopenia and decreased levels of the plasma cholinesterase enzyme [3]. Its recreational and abusive use has become a serious health problem in virtually all countries and Brazil [4]. During regional anesthesia, its use can cause hypertension, as well as ephedrine-resistant hypotension, combative behavior and altered pain perception. During general anesthesia, on the other hand, may exhibit hypertension (during intubation), cardiac arrhythmia and develop an acute myocardial infarction [5]. This study published in 2015, showed that there is a clear need for institutions to make practical guidelines or recommendations for the perioperative management of patients who abuse cocaine [5]. The education of doctors on the evidence that supports or refutes the safety of general or regional anesthesia in this scenario is equally important [5].

Cocaine metabolites have no stimulating action, and the test normally performed on urine remains positive for 6 to 14 days, so it is not a good marker for acute poisoning, reflecting only that it has been used in the recent past [6]. For the proper functioning of any surgical center, the cancellation of the surgery is an excellent indicator of its quality. Several hospitals remain using 7-day abstinence to perform surgery on cocaine users [7].

Recently, in an Editorial it was proposed to carry out studies to scientifically modify the surgery cancellation time in a cocaine drug addict patient [8], after the publication of two case reports with less than 31 hours of use [9].

Research is used in any branch of science. However, excellent research is much more difficult to carry out than it appears. Researchers in the field of anesthesiology use research to evaluate behaviors, attitudes and knowledge of both doctors and patients, or to determine the characteristics of the population, such as disease states, and practices or results [10]. Several surveys are now carried out through questionnaires with clear questions using the fewest possible high-quality essential questions that will interest the target population [10].

The present study was conducted specifically to assess the level of awareness about assessment and the criteria for anesthesiologists to stop surgeries in the face of cocaine addicted patients, through a questionnaire with four identification and seven objective questions in an accredited Hospital Brazilian Health Care System (SUS). The second objective was after the results of this questionnaire to create a new guideline to be implanted in a hospital with a high amount of anesthesia in patients using cocaine.

\section{Methods}

The study is a research of descriptive exploratory, prospective, transversally cut, quantitative, through the application of a questionnaire on anesthesia in patients using cocaine. The research was carried out at the large tertiary Hospital Clínicas Municipal of São Bernardo do Campo
(Brazilian System Health-SUS), newly accredited (International Qmentum Certification) with the anesthesiologist staff who perform their activities in number of 60 anesthesiologist. The inclusion criteria for this study were: Anesthesiologist staff of both genders, that accepted to participate in the study, and sign the Term of Informed Consent (TIC). Anesthesiology residents of the hospital were excluded.

The reason for the choice was the fact that the researcher works as an anesthesiologist in the Hospital, simplifying the work of data collection, and the study was registered in the Brazil Platform. Data collection was formalized by the approval by the Ethic Committee in Research numbered.

Data collection was carried out in the period to be determined from July to December 2020 with the aid of an instrument for data collection with four identification questions and five open questions relevant to the objective of the study (Appendix). The distribution and collection of questionnaires were provided by the researcher anesthesiologist.

To analyze the data, we use Descriptive Statistics graphs to profile the individual surveyed and build their respective distribution, in view of their use for visual representation of the information and to facilitate its interpretation. The respective graphs were constructed using an Excel spreadsheet and through the $\mathrm{R}$ Commander plug in for the $\mathrm{R}$ version 4.1.0 software available for free.

\section{Results}

Of the 60 staff of the Department of Anesthesiology 40 responded to the questionnaire making a percentage of $66.6 \%$ of participation, 12 women (30\%) and 28 men (70\%). For the study, two age groups were considered, with 20 participants between 27 and 35 years old and 20 participants over 35 years old.

The time of practice in the specialty ranged from 1 to 36 years, with 15 anesthetists from 1 to 5 years old, 15 anesthetists from 6 to 10 years old, five anesthetists from 11 to 20 years old and five over 21 years old. The average length of experience in the specialty who answered the questionnaire was $9.85 \pm 9.14$ years and the time working at the institution was $5.7 \pm 6.3$ years.

The fundamental research question (Number 5) showed that $75 \%$ of anesthesiologists cancel the surgery against $25 \%$ who refer the patient to the operating room.

Figure 1 shows the answers to the 1st question correlating with the presence of scheduled elective surgery in patients using cocaine, with all 40 anesthetists have always found cocaine users, varying according to the questions asked.

Figure 2 correlates whether there is a formal hospital policy regarding the use of cocaine, with $16(40 \%)$ anesthetists knowing that there is, 16 (40\%) anesthetists that there is a well-established consensus to suspend the surgery, with less than seven days of use, and $8(20 \%)$ anesthetists have no consensus.

Figure 3 shows $95 \%$ of anesthesiologists use the screening criteria that are based on the patient's clinical history of use or even the perception in the medical record. 
Citation: Marquezani MC, Imbelloni LE, Pöttker D, et al. (2021) Anesthesiologists' Conduct Assessment towards the User of Cocaine at SUS Hospital with Accreditation. Knowledge through Questionnaire. J Clin Anesth Pain Manag 5(2):227-231

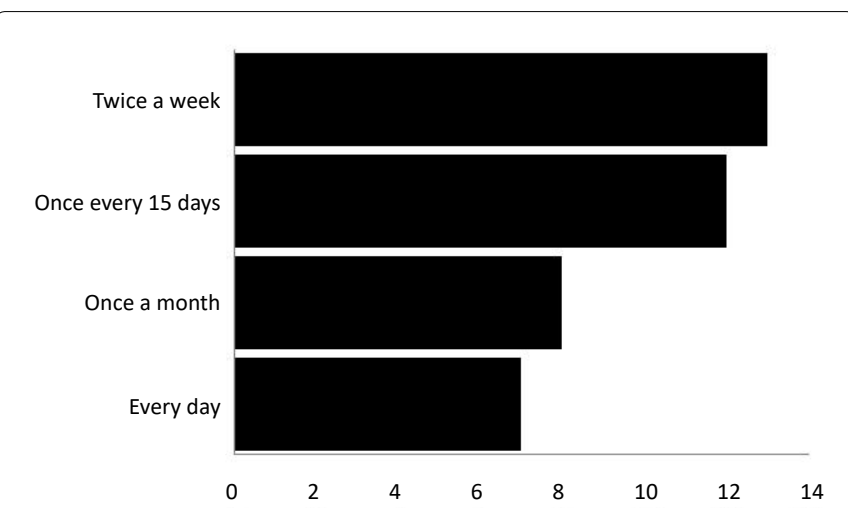

Figure 1: Answers to the $1^{\text {st }}$ question.

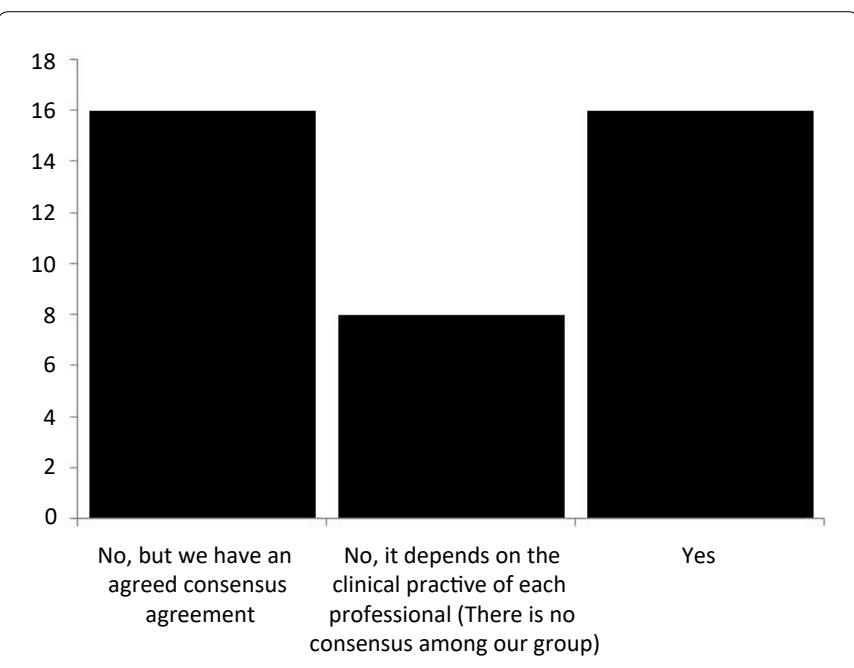

Figure 2: Formal hospital policy regarding the use of cocaine.

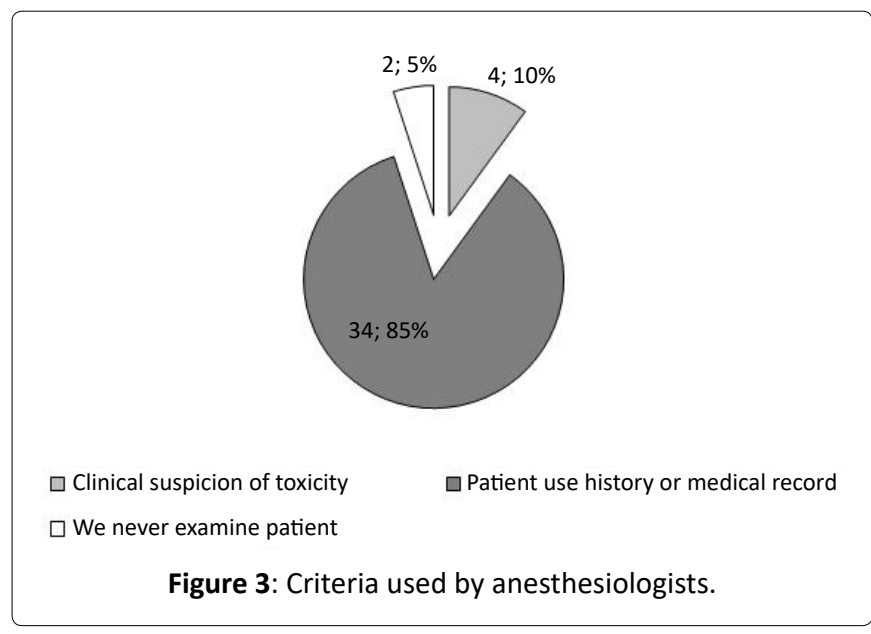

Figure 4 correlates when screening is performed and the majority (36 responses $=90 \%$ ) during the preoperative visit, the morning of the procedure, or both responses.

Figure 5 shows that $90 \%$ of anesthesiologists who cancel or postpone surgery in a percentage above $50 \%$.

Finally, Figure 6 shows the importance of having norms or guidelines for tracking the use of illicit drugs and especially cocaine, answered by 36 (90\%) of the 40 anesthetists consulted.

\section{Discussion}

Substance use disorder has three stages: Binge/intoxication, withdrawal/negative affect, and preoccupation/anticipation [11]. The anesthesiologist can usuallyintervene in any of these three stages. However, together with the interprofessional health team, an anesthetic plan must be developed after the Informed Consent Form has been informed and signed.In order to determine a guideline in our service, this questionnaire showed that $75 \%$ of anesthesiologists cancel the surgery against $25 \%$ who refer the patient to the operating room. And $90 \%$ of the anesthetists consulted believe that the Hospital must have a program and guidelines for performing surgery on cocaine users.

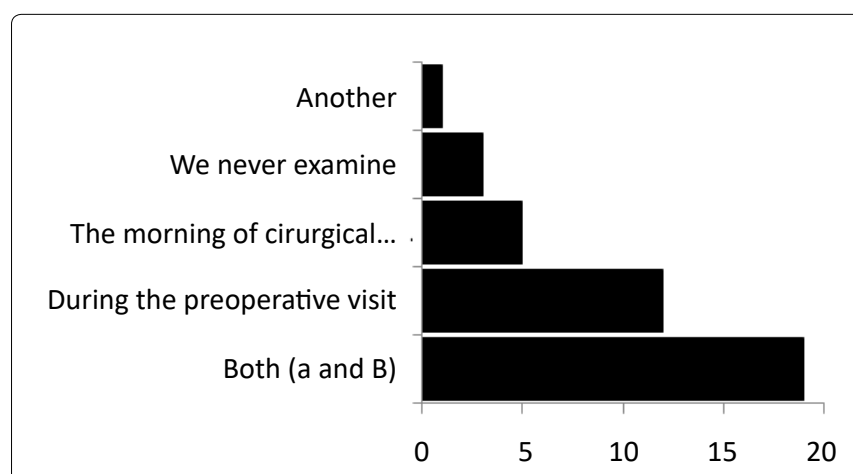

Figure 4: When the anesthesiologist examines the patient.

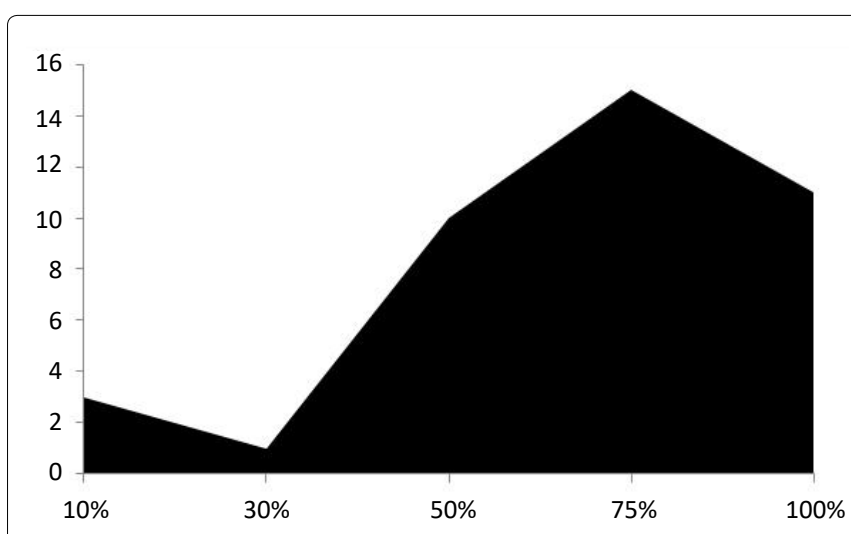

Figure 5: Porcentagem of surgery cancellation.

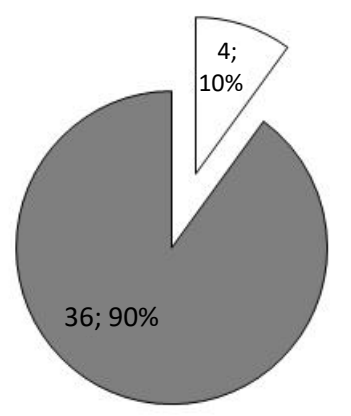

$\square$ Not very useful $\square$ Very useful

Figure 6: Need hospital guidelines. 
Citation: Marquezani MC, Imbelloni LE, Pöttker D, et al. (2021) Anesthesiologists' Conduct Assessment towards the User of Cocaine at SUS Hospital with Accreditation. Knowledge through Questionnaire. J Clin Anesth Pain Manag 5(2):227-231

The prevalence rates of snorted and smoked cocaine in Brazil suggests that the country is amongst thenations with greatest annual consumption rates becoming one of the biggest consumer markets of cocaineworldwide [12]. Prevention and treatment policiesshould take this into consideration and strengthen the focus oncocaine use in the country.

The expansion of cocaine use shows the need to create effective prevention strategies and the need for protocols to deal with these patients in hospitals, especially in emergency and surgery units. Our hospital serves a large number of patients who are victims of motorcycle accidents and the creation of a strict care protocol was the reason for knowing anesthesiologists' knowledge regarding this problem.Our survey through a questionnaire showed that all 40 (100\%) of anesthesiologists find patients using cocaine every month of the year.

Cocaine in any form is rapidly hydrolyzed in plasma with a half-life of around 90 minutes [6]. Its metabolites have no stimulating action, but the urine test can be positive for 6 to 14 days. Thus, the urine cocaine test is a poor marker for intoxication [13]. The cancellation of surgery among patients who screen positive for cocaine use is a common practicein many surgical centers. Because of these concepts, in a recent Editorial [8] and case report [9] it was proposed to review the seven-day time to wait for surgery should be a procedure to be reviewed.

Anesthesiologists should assume the importance of the pre-anesthetic visit, highlighting the greater propensity for perioperative complications in cocaine users.Our study showed that $95 \%$ of anesthesiologists use the screening criteria that are based on the patient's clinical history of use or even the perception in the medical record. It also showed that the majority ( $90 \%$ of anesthesiologists) perform the exam during a pre-anesthetic visit, on the morning of the procedure or in both situations. Finally, $90 \%$ of anesthesiologists believe that the implementation of guidelines on anesthetic conduct in cocaine users should be urgently implemented.

\section{Conclusion}

Drug abuse, especially with licit or illicit drugs, continues to grow worldwide and Brazil represents a large share $[12,14]$. Consequently, anesthesiologists may be involved in the care of patients under the acute and chronic influence of a myriad of substances. Anesthesiologists, as perioperative physicians, have a vital role to play in the comprehensive care in patients with addiction to licit / legal agents (eg. tobacco, alcohol) or to illicit / illegal drugs (heroin, cocaine, marijuana, etc.) [15]. This study of anesthesiologists' knowledge about cocaine use shows that they need to be proactive in obtaining a current or past history of drug abuse, modify the guidelines and understand that the metabolite present in the urine is a poor marker of acute intoxication, that is perfectly perceived by the clinical method.
The cancellation of surgeries is a topic being studied worldwide and that still requires investigations and interventions, as it is harmful to those involved and to the health system.

\section{Conflict of Interest}

The authors declare that this research was conducted without commercial or financial sponsorship that could lead to a potential conflict of interest.

\section{Acknoweldgements}

Residency Completion Work carried out at CET-SBA of Hospital Clinicas Municipal of São Bernardo do Campo, São Paulo, Brazil.

\section{References}

1. Niemann A (1860) Ueber eine neue organische Base in den Cocablättern. Archiv Der Pharmacie 153: 129-155.

2. Harper SJ, Jones NS (2006) Cocaine: What role does it have in current ENT practice? A review of the current literature. J Laryngol Oto 120: 808-811.

3. Bala N, Kaur G, Attri JP, et al. (2015) Psychiatric and anesthetic implications of substance abuse: Present scenario. Anesth Essays Res 9: 304-309.

4. Duailibi LB, Ribeiro M, Laranjeira R (2008) Profile of cocaine and crack users in Brazil. Cad Saúde Pública 24: S545-S557.

5. Elkassabany N, Speck RM, Oslin D, et al. (2013) Preoperative screening, and case cancellation in cocaine-abusing veterans scheduled for elective surgery. Anesthesiology Research and Practice 2013: 149892.

6. Brownlow HA, Pappachan J (2003) Pathophysiology of cocaine abuse. Eur J Anaesthesiol 19: 395-414.

7. Feinstein L, Schmidt K (2010) Cocaine users present unique anesthetic challenges: Part 2. Anesthesiol News 36: 30-31.

8. Imbelloni LE, de Araujo AA, Sakamoto JW, et al. (2020) The use of cocaine and derivatives and the cancellation of surgery. J Clin Anesth Pain Manag 4: 134-135.

9. Imbelloni LE, Vilela AC, Pistarino MA, et al. (2020) Spinal anesthesia and peripheral block for the cocaine abusing patient. Is it safe? A case report. Advance Research Journal of Multidisciplinary Discoveries 45: 17-20.

10. Story DA, Tait AR (2019) Survey research. Anesthesiology 130: 192-202.

11. Volkow ND, Koob GF, McLellan AT (2016) Neurobiologic advances from the brain disease model of addiction. $N$ Engl J Med 374: 363-371.

12. Abdalla RR, Madruga CS, Ribeiro M, et al. (2014) Prevalence of cocaine use in Brazil: Data from the II Brazilian National Alcohol and Drugs Survey (BNADS). Addict Behav 39: 297-301.

13. Cheng D (1994) Perioperative care of the cocaine-abusing patient. Can J Anaesth 41: 883-887.

14. da Silva KM, Quintana JB, González-Mariño I, et al. (2018) Assessing cocaine use patterns in the Brazilian Capital by wastewater-based epidemiology. International Journal of Environmental Analytical Chemistry 98: 1370-1387.

15. Steadman JL, Birnbach DJ (2003) Patients on party drugs undergoing anesthesia. Curr Opin Anaesthesiol 16: 147-152. 


\section{Appendix A}

\section{Data Collection Instrument}

\section{Identification:}

1. Gender: ( ) Male ( ) Female

2. Age: ( ) 27 to 35 years ( ) Above 36 years

3. Time in the area: ___ years

4. Time at the Institution:___ years

\section{Specific Questions}

1. How often does your area encounter cocaine abuse patients with scheduled elective surgery?

A. Every day

B. Twice a week

C. Once every 15 days

D. Once a month

E. Almost never

2. Do you have a formal policy for preoperative screening of patients for active cocaine use?

A. Yes

B. No, but we have an agreed consensus agreement

C. No, it dependes on the clinical practive of each professional (There is no consensus among our group)

3. What are your screening criteria for the use of cocaine in patients undergoing elective surgery?

A. Patient use history or medical record

B. Clinical suspicion of toxicity

C. We never examine patient

D. Other

\section{When do you screen for cocaine?}

A. During the preoperative visit

B. The morning of the surgical procedure

C. Both (A and B)

D. We never examine

E. Another

5. If a patient undergoing elective surgery is positive for cocaine use, his/her conduct regarding the procedure?

A. Cancel / Delay the procedure

B. Proceed to the operating room

6. What percentage of practitioners in your department will cancel or delay an elective procedure for positive cocaine screening?
A. $10 \%$
B. $25 \%$
C. $30 \%$
D. $50 \%$
E. $75 \%$
F. $100 \%$

7. Do you think that having norms or guidelines related to drug use tracking in patients with a history of cocaine use undergoing elective surgery would be helpful?

A. Very useful

B. Not very useful

C. Not useful

DOI: $10.36959 / 377 / 358$ 